\title{
ANALYSIS ON THE ENTROPIC MODEL OF THE INTELLECTUAL CAPITAL. CASE STUDY OF THE SMES IN THE NORTH EAST REGION
}

\author{
Andreea Feraru \\ “Vasile Alecsandri” University of Bacau \\ andreea_feraru26@yahoo.com \\ Roxana Mironescu \\ "Vasile Alecsandri” University of Bacau \\ roxy_mironescu58@yahoo.com \\ Ovidiu Leonard Turcu \\ "Vasile Alecsandri" University of Bacau \\ ovidiuturcu@gmail.com
}

\begin{abstract}
The intellectual capital in its dynamic approach focusses on the development of the entropic model, which expresses the dynamic transformation of the theoretical intellectual capital in a concrete and useful intellectual capital. The aim of the present paper is to perform a detailed analysis of the intellectual capital inside the SMES of the North-Est region of the country. It also speaks about the influence of the main integrators of the intellectual capital, divided into three elements: the cognitive, the emotional and the spiritual capital, about how they are acting as a field of forces upon the basic components of the intellectual capital, such as knowledge, intelligence and values and how they determine the generation and development of the intellectual capital in the eastern analyzed SMEs. Both jobs and teams inside the analyzed SMEs are stimulating the development of the intellectual skills, which reduces the need for involving the external experts, by appealing only those specialists who could transform the tacit knowledge into explicit knowledge. The organizational communication provides the necessary information and contributes to the establishment of a fair climate and of the effective relationships between managers and employees, between work mates, and also with the people outside the organization.
\end{abstract}

\section{Keywords}

intellectual capital; knowledge; intangible resources; small and medium enterprises; new competitive economy

\section{JEL Classification}

M10

\section{Introduction}

The conceptual development of the intellectual capital was made from two different but converging directions. The first direction was generated by the need to increase the competitive ability of the company and achieve strategic advantages in the more competitive markets by intensively capitalizing the intangible resources. Among these resources the attention has focused on information and knowledge, trademarks and patents, on the organizational behavior and the oriented organizational culture towards excellence. In other words, the question is how an intangible resource management can be more efficient inside a company in order to increase its competitiveness. The second direction was generated by the evident tendency to strengthen the company's success ratio between the market value and the growing financial value. 
The overwhelming majority of the authors treat the intellectual capital as a organizational resource, structured as follows: the human capital, the structural capital and the relational capital. Regardless of the titles used, the mentioned static models speak about the manifestations of the organizational intellectual capital, long after its occurrence (Stewart, 1998; Roos et al., 1997; Sveiby, 1997; Andriessen, 2004). Therefore, all these studies have a static nature, they design a taxonomy on a real date and not a dynamic reality in its progress. The most commonly used classification is the one which divides the intellectual capital into three components: human capital, relational capital (customers) and structural capital. Stewart attributes this taxonomy to Leif Edvinsson from Skandia and to Hubert Saint Onge. However, it should be noted that Leif Edvinsson, according to the Market Value Scheme divides the intellectual capital into human and structural capital, which consists of the customer capital and organizational capital, the latter being composed of the innovative capital and the capital processes. Although it seems to be well structured, this classification uses groups of entities that are not well enough defined, nor unique. For example, the structural capital includes the organizational capital, although the structure is part of an organization and not vice versa (Brătianu, 2006). Thus, more and more authors use, in their efforts, the empirical classification of the intellectual capital divided in human, structural (organizational) and relational capital (customers). In the context of an economy in continuous transformation and evolution, the most important resource of any company is the human capital. But the mere presence of a number of employees is not enough for build the value of an organization, the human resources represents and there actually is a competitive advantage, by the staff quality, by their skills, abilities, knowledge and their orientation towards performance and success.

Is it enough the employees' involvement and a performance-oriented environment that stimulates creativity and innovation to succeed in the long term business? Surely it is not enough because as an organization is not alone on the markets, it acts in a complex environment and it is directly or indirectly linked to various organizational players in the entire world (stakeholders, customers, suppliers, shareholders, public institutions etc.). That is why the relational component of the intellectual capital is as important as the human and structural components. The organization should focus its efforts on financial and human topics and on maintaining long term relationships with all the business partners, with the target markets and with the society, in its expanded interpretation.

\section{The entropic model, a new and modern perspective on the intellectual capital}

The new knowledge society is characterized by strong nonlinear and dynamic processes. For the organizations, in order to survive and become more competitive in an uncertain future, in a foreign changing environment, it should be necessary to promote the nonlinear system. They operate with very good results in the linear areas of our work, as the valorization of our intellectual capital. In other words, the organization is regarded as a variety of force fields that interact with each other and act on the primary constituents of intellectual capital: knowledge, intelligence and values, for the generation and the development of the intellectual capital.

The intellectual capitulation is a vague and somewhat confusing concept; its limits are not well defined, and interact with the common interpretation of the human capital concept. For example, Stewart considers the intellectual capital as "the sum of all the things that everybody in a company know, that gives it a competitive advantage," or "the intellectual capital is made by its raw material - knowledge, information, intellectual property, know how - that can be used to create wealth. It may be the collective brainpower "(Stewart, 1998). It is enough to analyze the Andriessen's 
theory or other contributions in this field (Andriessen, 2004). In many of these, the intellectual capital of an organization includes: human, structural and organizational capital, relational or customer capital. The human capital is fundamental because it is the source of innovation and renewal, and it represents the employees' capabilities to provide solutions for the customers. The structural capital of an organization make possible all those relationships that facilitate the change of the intellectual potential into concrete actions, in order to create such a value which is reflected in the products and services offered by the organization to the markets. The relational capital represents the value of the relationships we have with the organization (Stewart, 1998, p.110). This general structure of the intellectual capital is a static and holistic one, it does not show how the value of the potential capital increases and how to transform a large part of the existing capital in action and value.

The wide range of definitions and approaches to the concept of intellectual capital show their importance, but at the same time, the difficulty of expressing something as "untouchable". Davenport Th. and Laurance Prusak's definition presented in Stewart's book named "Intellectual Capital - The New Wealth of Organizations", is the following: "some intellectual matter that has been formalized, captured and used to produce an asset of greater value" (Davenport and Prusak, 2000). But this definition is not very clear in terms of the tacit knowledge, which is very difficult to express and to share with others. In the same book there is another definition, which did more than describe the role of the intellectual capital inside an organization, rather than defining it: "The knowledge that exists in an organization that can be used to create a competitive advantage" (Stewart, 1998). Leif Edvinsson, Skandia, and Pat Sullivan define the intellectual capital as "knowledge that can be converted into value" (Sveiby, 2001). It is a very simple definition, but it is not necessarily a comprehensive interpretation. As it can be seen from the above definitions, it is quite complicated that a definition containing some few words can capture the essence of the concept of intellectual capital and to provide a complete picture of the conceptual and practical essence. Therefore, both practitioners and researchers in the field prefer to use as a starting point in their approaches different classifications of the intellectual capital components. For example, there are few models of measurement / evaluation of the intellectual capital that do not use such a classification we mentioned above.

Davenport's and Prusak's vision about knowledge is that it derives from the intellectual work. Knowledge is defined as "a continuous mix standard experiences, values, contextual information and expertise that enable the creation of a framework for evaluating and incorporating new information and experiences" The knowledge has its roots in the minds of the connoisseurs. The authors highlight the fact that the knowledge of an organization is embedded not only in documents and databases, but are also in processes, practices, standards. "In the opposite side of the individual knowledge, there is the organizational knowledge that is very dynamic: there is variety of forces which are working on it" (Davenport and Prusak, 2000). Knowledge is dynamic if it is created as a result of the social interactions between individuals and organizations.

The intelligence, in its classical vision, is the cognitive ability of an individual. In 1983 Gardner has introduced a new concept, namely multiple intelligence, which is defined, in his view as "multiple intelligences theory that involves a passage to the plural concept of intelligence". Intelligence is the ability to process a particular type of information and it has its origins in biology and human psychology" (Gardner, 2006). The values are beliefs about what is right or wrong and what is important in life, being fundamental to define the behavioral model, especially in the process of making decisions: "Values are more important to take a decision than the alternatives. Just ask yourself why you should make the effort to choose an alternative than to simply leave it to the chance. The answer must be the alternatives which have 
different consequences for your value system" (Brătianu, 2009). The essence of our personality and value put its mark on the way one behave and on his actions, it is deeply rooted in our childhood education, it also can be considered as a system of beliefs about a person's relative value, of a place, of an event or a thing relative value, as we are parts of a cultural matrix and we get all this cultural, ethical, moral and religious substance from the family, school, church, community, university and/or the organization where we work. Therefore, each value represents the learned concept during our life.

Unlike other models, the entropic model captures the dynamic transformation of the intellectual capital from a potential intellectual to an useful capital, as in physics the energy models reflects the transformation the potential energy of a body or of a mechanical system into kinetic useful energy. In a first stage, the individual contributions of each employee in the form of knowledge, ways of thinking, emotions, behavior patterns and values are transformed into organizational capital with the help of the integrators.

The entropic model of the intellectual capital suggests a new approach of the entire structure of the organizational intellectual capital, including integrators and vision, as a leading force. The innovation and learning in the organization are the main mechanisms of the intellectual capital renewal. The new model is based on the assumption that the organizational intellectual capital is a complex and dynamic system, fueled by the integrators and lead by vision. The model of the entropic intellectual capital has been created by Bratianu and published progressively in a series of papers (Bratianu, 2008; Bratianu \& Orzea, 2013).

This new entropic intellectual capital includes four main ideas:

- the organizational intellectual capital is a result of complex interactions and of the dynamics between three fields: the cognitive knowledge field, the emotional knowledge field and the spiritual knowledge field;

- the organizational intellectual capital is conceived as both a potential and as an operational capability. The potential intellectual capital can be transformed into operational intellectual capital through integrators. The operational intellectual capital can be also transformed into intellectual capital potential through the dynamic capabilities of the organization;

- the organizational intellectual capital is conceived as a complex adaptive system that includes dynamic capabilities needed for adaptation and renewal, especially through innovation and learning;

- the organizational intellectual capital is projected towards a vision for the future, mainly, in order to obtain a competitive advantage (Brătianu et al., 2012).

In any organization, there are three fields of knowledge: knowledge of the field of cognitive, emotional and spiritual components, which are in a continuous dynamic evolution. This means that some form of information may be transformed into another kind of information, as in the case of physics, where a physical form of energy may be converted into another form of energy under the action of a force field. This force field is able to integrate individual knowledge (cognitive, emotional, and spiritual), individual energy and personal motivation. The energy and the motivation of the organization is more than the sum of all the individuals' energies and motivations. This combining process is highly nonlinear, and the final result heavily depends on the power of the integrative forces.

The fields of knowledge are strongly nonlinear and uneven and changing each field generates streams of knowledge that can be converted into knowledge transfer processes when individual and organizational barriers can be overcome. Every form of knowledge can be processed by a specific intelligence, so that the entire organization gets a final result, namely organizational intellectual capital. A schematic representation of this complex is shown in Figure 1. 


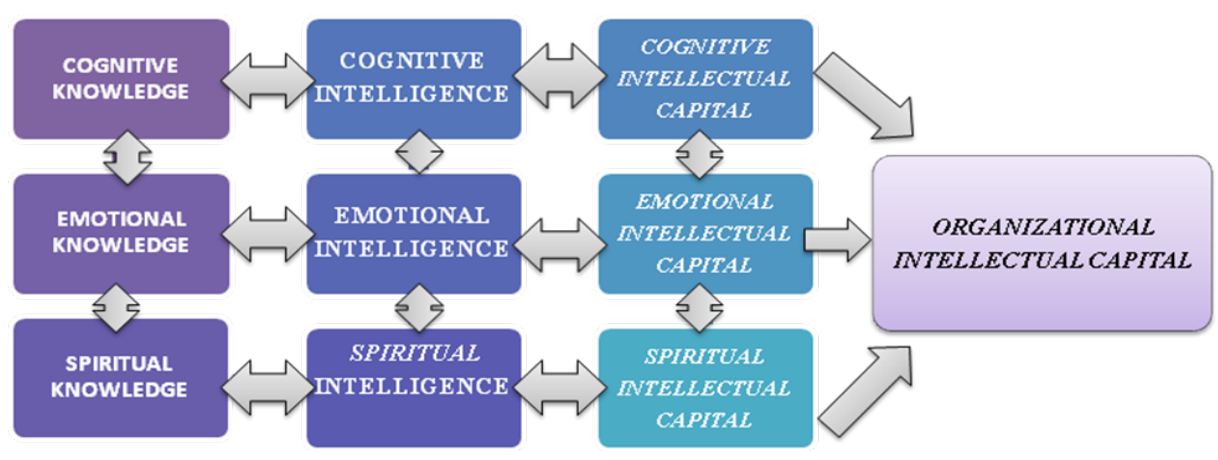

Figure 1 The integrating model of the intellectual capital, in a sketchy presentation. Source: Bratianu \& Orzea, 2013, p.137

In this new perspective, the companies that have the same potential intellectual capital may have different results if they have different levels of the operational intellectual capital as a result of the different work performed by their organizational integrators. Thus, an organization cannot ask people to be creative by applying a simply managerial authority. All the managers can do is to create the favorable climate, the feeling of freedom, of security, to develop creativity, innovation, they can create an oriented toward knowledge organizational culture. A strong organizational culture that appeal intelligences, the individual values and generates a spirit of excellence, may achieve the development of the intellectual capital with a great potential for innovation and creativity. This culture can be built by strengthening the importance of creating new knowledge, not just in meetings but also through the introduction of performance criteria related to knowledge creation and rewarding the employees who succeed to achieve the goals imposed by the performance criteria. Individualized rewards can be developed, in order to recognize the creativity and knowledge creation inside the organization.

Closely linked to a strong organizational culture there is the trust among the employees. Informal meetings, both at work and outside the enterprise, lead to the building and developing a sense of trust between the employees and therefore, it can increase the amount of new knowledge created. When individuals face, in an informal environment, certain common challenges, each of them creates and thinks the problem and the solution in terms of his individual thought patterns. Thus, the result is a symbiosis of perspectives and variety and these perspectives facilitate the "creative abrasion" The "Creative Abrasion" is accomplished by creating an atmosphere where ideas are continuously being challenged and new interpretations are constantly made. The idea of "creative abrasion" is specific for the collaborative team environment. An example of successful "creative abrasion" is in the design of the first Macintosh computer. In setting out to create the Macintosh, Steve Jobs assembled a diverse team composed of musicians, artists, and others. All of them were qualified as efficient software people as well, but it was their other more creative talents that Jobs valued. (http://monstahsoxfan.blogspot.ro/2012/02/creativeabrasion.html). A symbiosis is required and this is achieved through discussions between employees, where opinions are informally exchanged, while building a sense of trust and informal relations. 


\section{Study on the integrators of the intellectual capital in the SMEs from the North East region}

The objective of this research was to identify the internal major factors which influence the intellectual capital management in the present and the future for the SMEs in the North East region. The existence of the organizational integrators, for creating the entropic model of the intellectual capital, such as the motivating and stimulating systems, the organizational culture based on creativity and innovation, the team working and the powerful values there are the main aspects this study has wanted to underline. This research is part of a larger inquiry upon the features of the intellectual capital of the north eastern SMEs, during 2013.

The method used in this paper work is based on a questionnaire to a sample of 120 top managers of the SMEs in the North East region, coming from various fields of activity, operating on the market for more than two years. The management of information and the data collection was conducted in the middle of 2013.

The main objectives of the present study were:

- What are the most important values the managers coming from the analyzed SMES recognize;

- The emotional and the relational capital are recognized and valued inside the SMEs?;

- What are the strategies for the future management of the intellectual capital in these SMEs;

- What are the tools of the organizational culture to keep the employees appreciated and motivated to efficiently work and to generate knowledge and performance.

In the Romanian business environment a great importance is allocated to the organizational culture and the organizational mission and vision, during the processes of generating and developing the intellectual capital and the organizational knowledge. Based on this principle, the SMEs' managers were questioned about the existence of a set of professional and ethical values among their employees. The results can be seen in the following graphic (see graph.1):

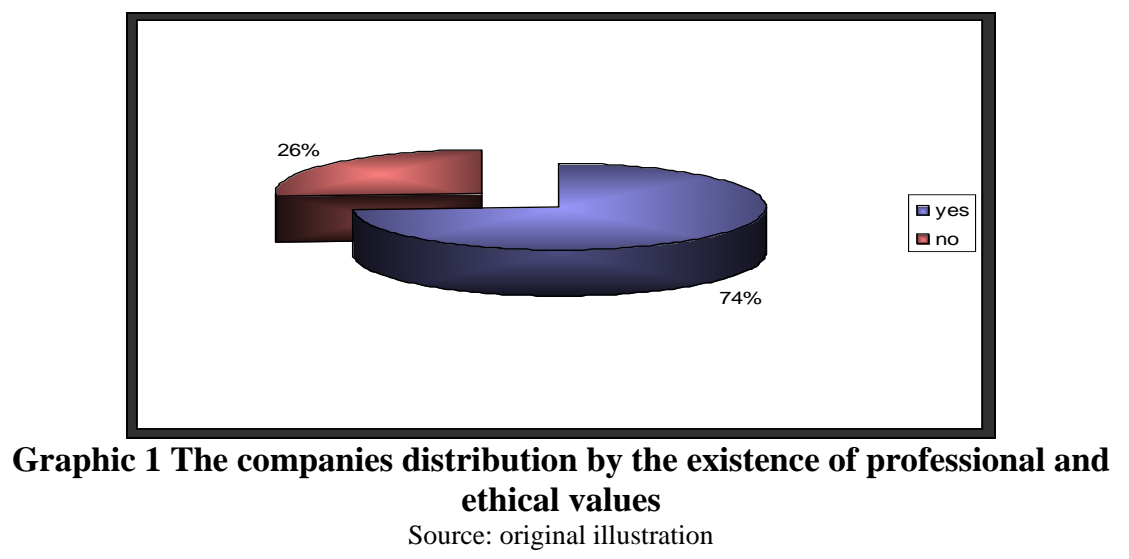

Analyzing the obtained responses one can see that $74 \%$ of respondents have a set of well-defined professional and ethical values, also learned and practiced by the employees, on the opposite side, $26 \%$ of respondents have a set of values, but they are not acquired by their employees. The main professional and ethical values for those $74 \%$ of respondents there are: (see graphic 2) 


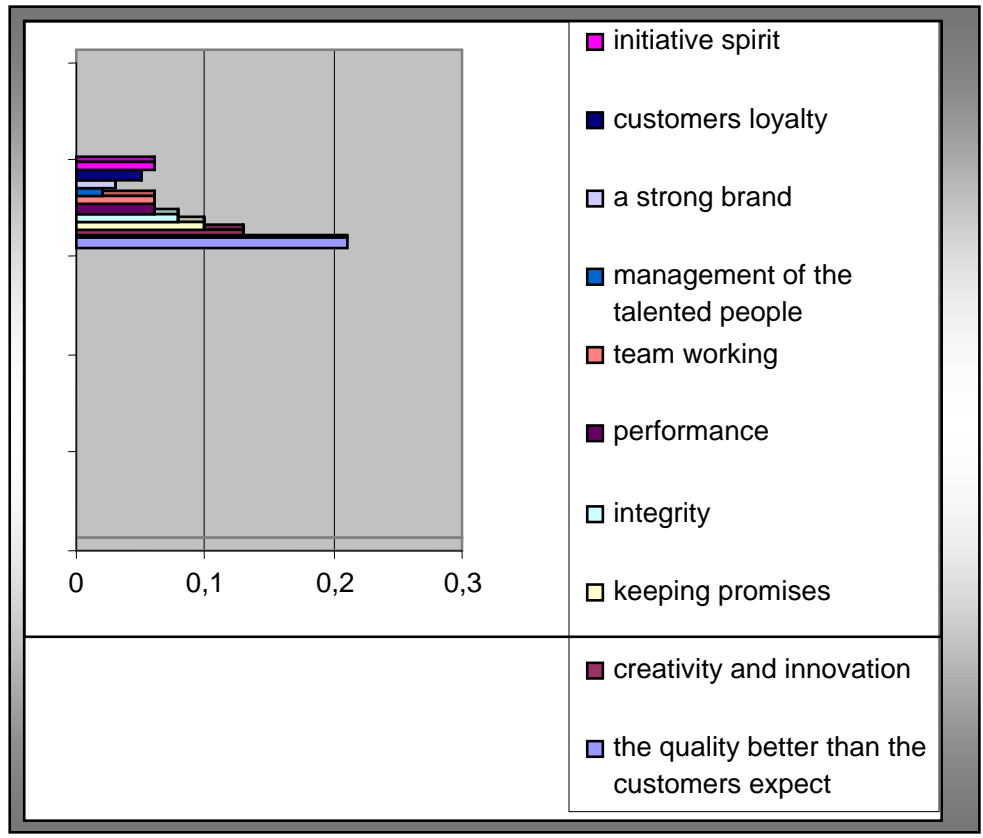

\section{Graphic 2 The most important values and professional ethics adopted in the studied enterprises. \\ Source: original illustration}

From the above it can be said that in the respondents' top professional values and ethics are the concern for high quality products and services with a share of $21 \%$ followed by the creativity and innovation with $13 \%$, the integrity has obtained $8 \%$, the performance and work team $6 \%$ of the total amount of responses of the managers who recognized values and ethics. The trend to invest in human resources is the consequence of the current economic crisis, because the difficult conditions require the existence of the efficient, skilled and adaptable employees, responsibly acting in such an environment. Only the those SMEs which will realize the importance of the organizational culture influence upon the each employee's fundamental values, will survive and will leave values over the time, not just some product / service or profits. The employees' skills and their intellectual abilities are considered as personal characteristics that employees need to perform work, related to the hierarchical occupied positions. Within these, certain aspects can be included, such as education, technical and professional knowledge, academic qualifications, training and experience needed by the employees, the manual and intellectual skills, the interpersonal skills and the ability to work in leadership teams. A vital element of the evaluation of the intellectual capital is the need to harmonize the exceptional powers and attributes of the employees with the changing demands of the held position, and thereby to influence their behavior. It should be noted that the employees are the human capital of an organization, but not the organization itself, therefore managers must bear in mind that this wrong approach may determine the employees to leave the organization, generating an imbalance of the internal intellectual capital. Thus, deeply knowing and understanding the primary constituents (the employees' skills and their intellectual ability) are the major premise for underlying the valuation of the human capital. 


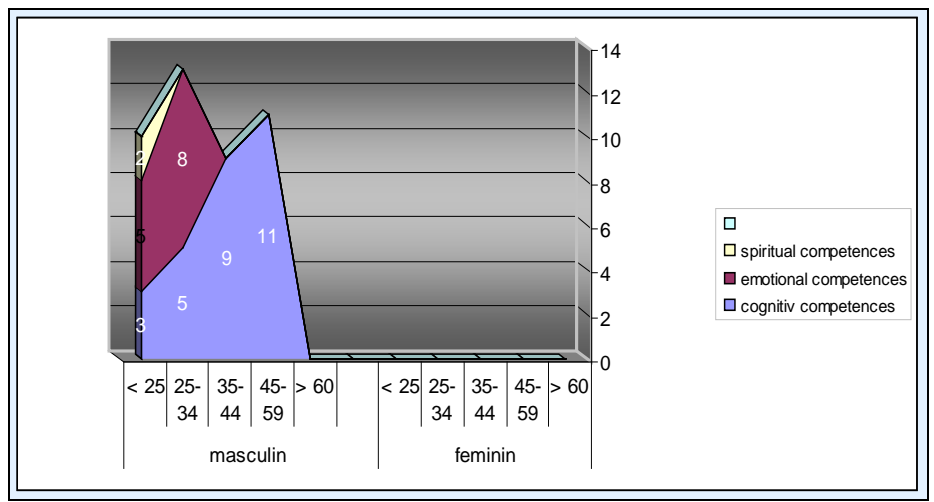

\section{Graphic 3 The employees' assessment based on cognitive, emotional and spiritual competences \\ Source: original illustration}

Employees of SMEs surveyed are valued by:

- $66.67 \%$ of men aged over 60 primarily appreciate the employees by their cognitive skills, compared to $50 \%$ of women the same age;

- $\quad 50 \%$ of women under 25 and over 60 years appreciate the employees by their emotional competencies, compared to $42.85 \%$ of men aged between 25-34;

- $\quad 50 \%$ of women aged between 25-34 considered the spiritual powers another employee' criterion of evaluation and assessment, unlike $40 \%$ of men under 25 .

An enumeration made by the interviewed managers about the main methods used to motivate employees of the companies they run can be seen in graphic 4 :

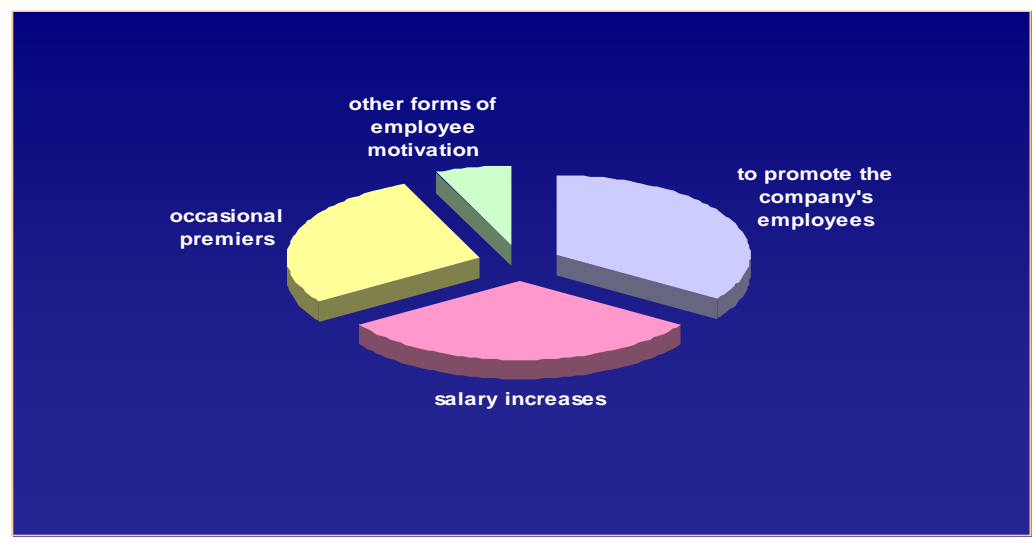

\section{Graphic 4 The motivating and stimulating strategies in the SMEs analyzed \\ Source: original illustration}

From the analysis we can see that a majority of SMEs effectively use the strategies to motivate and stimulate the employees, with a rate of $34.37 \%$ for the promotion, followed by $31.25 \%$ salary increases and occasional awards $28.12 \%$.

Analyzing the information obtained from the actual data collection and from the processing in our conducted research, we found that:

- $\quad$ the businesses are striving to reward their employees' work and to retain them as much as it is possible in order to benefit of their individual skills. The great importance of the human capital in the structure of the intellectual capital is given 
by the involvement of all its components in performing any activity carried out by the surveyed SMEs in the North East region of the country;

- $\quad$ The open cultures encourage people to share common ideas and knowledge, thus using various communication channels. Also, an open culture is one where people participate due to a sense of commitment and solidarity;

- The interviewed managers recognized that the existence of the values is well known, it is accepted and embraced by the employees and it helps to raise the level of loyalty and attachment to the company targets. People can be more motivated to achieve common goals, which would lead to a high efficiency and high performance, by sharing common values and objectives;

- Managing agreeable and effective relationships with customers should be, added to the value provided and incorporated in merchandises, an important tool to generate their loyalty;

- The value of the relationships the organization has with its customers has to be improved with the stakeholders' relations without any organization could not survive. Thus, the relational capital becomes an intangible asset that is based both on maintaining the best possible relations with the other SMEs in the North East region of the country, with individuals or groups and the development of these relationships that contribute to the performance improvement of the analyzed SMEs. The relational capital is also important because it helps in increasing the value of the human and structural capital, due to the ability of the SMEs from the North East region of the country to interrelate with their stakeholders in a positive manner;

- The valorization of the spiritual, the emotional and cognitive intellectual capital can increase the power of the brand for certain open markets of the analyzed SMEs;

- The intellectual capital, whether it is practical or not, it exists in any organization, active or inactive; it does not matter the form it is presented, it certainly influences the quality of the human resources and the whole organization for its market image,

\section{Conclusions}

In the knowledge economy the main challenge is to build, to combine and to integrate thousands of employees' knowledge in an organizational background. This means to create an environment where knowledge can be acquired, transferred and easily used. Therefore, the modern organizations are willing to accept the new challenges coming from the knowledge economy, but they will need to evolve towards becoming generating organizations, integrative ones and not least, protecting knowledge organization. Investing in knowledge lead to productivity and an efficiency more and more growing. The need for training, manifested by the employees' majority reflects the desire to encourage them to directly or indirectly share knowledge with their team mates and it is perhaps the most natural way to transmit knowledge from one individual to another.

The competitiveness of the north eastern SMEs on the regional, national and international markets depends on the managers' favorable attitude about the importance of managing the intellectual capital that is why it becomes important and necessary to create a powerful organizational culture, as a favorable field for the entropic model of the intellectual capital. 


\section{References}

Andriessen, D. (2004), Making Sense of Intellectual Capital - Designing a Method for the Valuation of Intangibles, Butterworth-Heineman, Burlington (MA) and Oxford (UK).

Brătianu, C. (2006), Un model de analiză a capitalului intelectual organizațional, Management \& Marketing, vol. 1, nr. 3.

Brătianu, C. (2009), The frontier of linearity in the intellectual capital metaphor, Electronic Journal of Knowledge Management, vol. 7, issue 4.

Brătianu, C., Dima, A.M., Vasilache, S., Orzea, I. (2012), Nonlinear integrators and intellectual capital dynamics. Bucureşti : Editura Curtea Veche.

Bratianu, C., Orzea, I. (2013), The entropic intellectual capital model, Knowledge Management Research \& Practice, (2013) 11, 133-141.

Davenport, T.H. si Prusak, L. (2000), Working Knowledge, Harvard Business School Press, Boston.

Gardner, H. (2006), Multiple intelligences, New Horizons, New York.

Stewart, T. (1998), Intellectual Capital, The New Wealth of Organizations, London, Nicholas Brealey Publishing House.

Sveiby, K.E. (2001), Intellectual capital knowledge management, available at http://sveiby.com/articles/IntellectualCapital.html.

Roos, G., Roos, J. (1997), Measuring your Company’s Intellectual Performance. Long Range Planning, Special Issue on Intellectual Capital, vol. 30, No.3. 